07.2

\title{
Мемристоры на основе поли-n-ксилилена с внедренными наночастицами серебра
}

\author{
(C) А.Н. Мацукатова ${ }^{1}$, А.В. Емельянов ${ }^{2}$, А.А. Миннеханов ${ }^{2}$, Д.А. Сахарутов ${ }^{2}$, А.Ю. Вдовиченко ${ }^{2,3}$, \\ Р.А. Камышинский ${ }^{2,4}$, В.А. Демин ${ }^{2}$, В.В. Рыльков ${ }^{2,5}$, П.А. Форш ${ }^{2}$, С.Н. Чвалун ${ }^{2,3}$, П.К. Кашкаров ${ }^{1,2,6}$ \\ ${ }^{1}$ Московский государственный университет им. М.В. Ломоносова, Москва, Россия \\ ${ }^{2}$ НИЦ „Курчатовский институт“, Москва, Россия \\ ${ }^{3}$ Институт синтетических полимерных материалов им. Н.С. Ениколопова РАН, Москва, Россия \\ ${ }^{4}$ ФНИЦ „Кристаллография и фотоника“ РАН, Москва, Россия \\ ${ }_{5}^{5}$ Фрязинский филиал Института радиотехники и электроники им. В.А. Котельникова РАН, Фрязино, Московская обл., \\ Россия \\ ${ }^{6}$ Санкт-Петербургский государственный университет, Санкт-Петербург, Россия \\ E-mail: an.matcukatova@physics.msu.ru
}

Поступило в Редакцию 9 октября 2019г.

В окончательной редакции 9 октября 2019г.

Принято к публикации 15 октября 2019 г.

\begin{abstract}
Изучены свойства мемристоров на основе поли- $n$-ксилилена с наночастицами серебра: их вольт-амперные характеристики и эффект резистивного переключения, устойчивость к циклическим переключениям и возможность хранения резистивного состояния во времени. Обнаружено, что внедрение наночастиц приводит к существенному улучшению основных мемристивных характеристик. Полученные результаты могут быть использованы для создания больших массивов мемристоров с однородными характеристиками, эмулирующих синапсы в нейроморфных вычислительных системах.
\end{abstract}

Ключевые слова: мемристор, органическая электроника, поли- $n$-ксилилен, нанокомпозит.

DOI: 10.21883/PJTF.2020.02.48948.18064

В последнее время существенно возрос интерес к структурам, демонстрирующим эффекты обратимого резистивного переключения (РП), благодаря перспективности их использования для создания элементов многоуровневой памяти и массивов мемристоров, эмулирующих синапсы в нейроморфных (биоподобных) вычислительных системах (НВС) для решения так называемых антропоморфных задач [1-3]: распознавания образов и естественного языка, принятия решений, обобщения, прогнозирования и др. Такого рода системы обладают малым энергопотреблением и могут существенно превосходить по эффективности обработки информации современные вычислительные системы, базирующиеся на архитектуре фон Неймана, при выполнении перечисленных выше когнитивных функций [4].

Критическими параметрами для использования мемристора в НВС являются число стабильных (без деградации) циклов РП из высокоомного $\left(R_{o f f}\right)$ в низкоомное $\left(R_{\text {on }}\right)$ состояние и обратно, отношение $R_{\text {off }} / R_{\text {on }}$, возможность установления произвольного резистивного состояния структуры в интервале между $R_{o n}$ и $R_{o f f}$, длительность хранения резистивных состояний, а также отсутствие электроформовки [5]. Большинство мемристивных устройств на данный момент изготавливается с использованием неорганических материалов $\left(\mathrm{TiO}_{2}, \mathrm{ZnO}, \mathrm{HfO}_{2}, \mathrm{WO}_{3}, \mathrm{SiO}_{2}\right.$ и др.) [6-9]. Наряду с неорганическими мемристорами все больший интерес начинают вызывать мемристоры на основе органических материалов, так как они не уступают неорганическим по основным параметрам [10], но при этом обладают рядом преимуществ, например относительно малой стоимостью, простотой изготовления, гибкостью и биосовместимостью $[11,12]$. Одним из перспективных органических материалов для создания мемристоров является поли- $n$-ксилилен (PРX) [13]. Мемристоры на основе РРХ имеют высокое значение отношения $R_{o f f} / R_{o n}$, большие времена хранения резистивных состояний, многоуровневый характер РП [14]. Однако количество циклов переключения для таких структур остается низким, а разброс напряжений переключения может достигать больших величин (десятки процентов) [11].

Одним из подходов для повышения стабильности РП является внедрение металлических наночастиц (НЧ) в слой диэлектрика в структуре металл/диэлектрик/металл $[15,16]$. Металлические НЧ выступают в качестве концентраторов электрического поля и, как следствие, стабилизируют и облегчают процесс РП (отсутствует необходимость электроформовки). Наиболее распространенными способами внедрения металлических НЧ являются имплантация ионов с последующим отжигом [9] или использование композитных мишеней при распылении, при котором в процессе осаждения формируется наногранулированная металлдиэлектрическая пленка [16,17]. Второй метод более предпочтителен, так как не требует высоких температур.

До сих пор повышение стабильности органических мемристоров на основе РPX за счет внедрения металлических НЧ не изучалось. Поэтому цель настоящей 

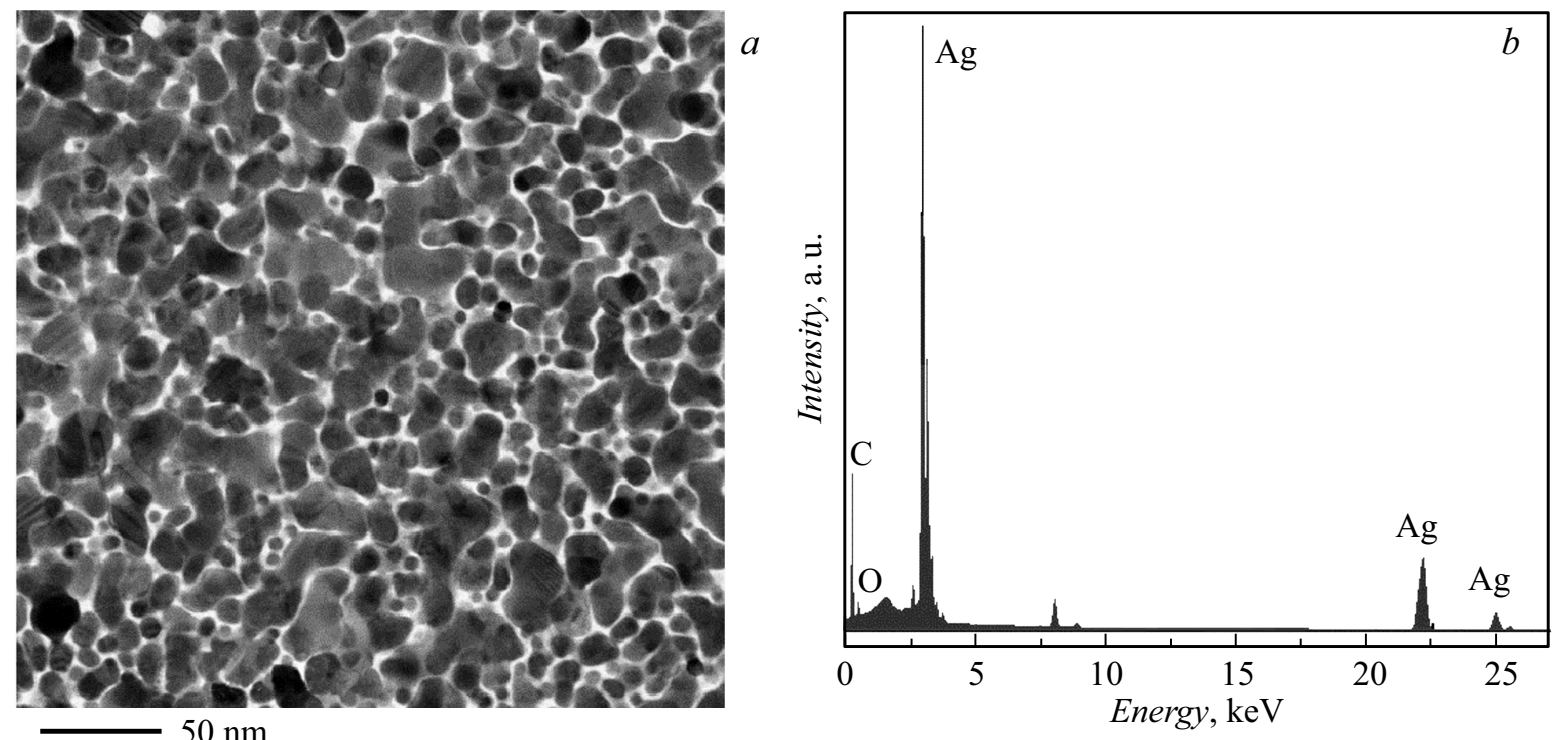

Рис. 1. $a-$ ПЭМ-изображение микроструктуры слоя $\mathrm{PPX}-\mathrm{Ag}$ в светлом поле в масштабе $50 \mathrm{~nm} ; b-\mathrm{cпектр} \mathrm{слоя} \mathrm{PPX}-\mathrm{Ag}$, полученный с помощью ЭРМ.

работы заключается в исследовании мемристивных характеристик конденсаторных структур на основе PРX с НЧ серебра, внедренными в процессе роста пленки РРХ.

В работе рассмотрены мемристивные сэндвич-структуры, состоящие из нанокомпозита PPX-серебро (PPX-Ag), осажденного на стеклянную подложку со слоем оксида индия-олова (ITO), который выступал в качестве нижнего электрода (далее структура обозначается как $\mathrm{Ag} / \mathrm{PPX}-\mathrm{Ag} / \mathrm{ITO})$. Синтез нанокомпозита осуществлялся по методике, описанной в [18]: в высоком вакууме $\left(10^{-5}\right.$ Torr $)$ сублимировали исходный прекурcop - пара-циклофан - при температуре $60-90^{\circ} \mathrm{C}$; затем он, попадая в зону пиролиза, при $650^{\circ} \mathrm{C}$ разлагался на мономер - пара-ксилилен. Мономер осаждался на подложки, охлажденные до $77 \mathrm{~K}$, одновременно с парами металла, получаемыми термическим испарением. Далее метастабильный соконденсат $n$-ксилилена и серебра разогревался и самопроизвольно полимеризовался, образуя нанокомпозит. После этого осаждался верхний металлический электрод термическим распылением серебра через теневую маску размером $0.2 \times 0.5 \mathrm{~mm}$.

Микроструктура пленки $\mathrm{PPX}-\mathrm{Ag}$ изучалась с помощью просвечивающего/растрового электронного микроскопа (ПЭМ/ПРЭМ) Titan 80-300 (FEI), оснащенного корректором сферических аберраций, высокоугловым кольцевым детектором темного поля и системой энергодисперсионного рентгеновского микроанализа (ЭРМ). Мемристивные характеристики структур $\mathrm{Ag} / \mathrm{PPX}-\mathrm{Ag} / \mathrm{ITO}$ исследовались с помощью аналитической зондовой станции Cascade Microtech PM5. Импульсы напряжения подавались на верхний электрод (при заземленном нижнем электроде) от источникаизмерителя National Instruments PXIe-4140, запрограммированного в среде LabView. Bсе эксперименты вы- полнялись при комнатной температуре. Для измерения вольт-амперной характеристики (BAX) подаваемое на мемристоры напряжение увеличивалось от нуля до положительного напряжения $U_{+}$линейно по времени, далее понижалось до отрицательного напряжения $U_{-}$, а затем вновь повышалось до нуля. Напряжение изменялось с шагом $0.1 \mathrm{~V}$ при длительности каждого шага $100 \mathrm{~ms}$. Для того чтобы при больших напряжениях не происходило теплового разрушения мемристоров, ток ограничивался на уровне $1 \mathrm{~mA}$.

На рис. 1, $a$ представлено ПЭМ-изображение пленки нанокомпозита PPX-Ag. Четко видна его гранулированная структура (темные области соответствуют положению НЧ серебра) с характерным размером частиц 10-20 nm. Концентрация серебра в слое нанокомпозита была определена методом ЭРМ и составила около 18 vol.\% (рис. $1, b)$.

На рис. 2, $а$ представлена типичная ВАХ исследованных мемристивных структур. При приложении положительного напряжения $U_{\text {set }}$ мемристор переводится в состояние $R_{o n}$, а при приложении отрицательного напряжения $U_{\text {reset }}-$ в состояние $R_{\text {off }}$, причем отношение сопротивлений в этих состояниях $R_{\text {off }} / R_{\text {on }}$ доходит до $10^{3}$. Напряжения переключения $U_{\text {set }}$ и $U_{\text {reset }}$ варьируются от цикла к циклу и от образца к образцу, что следует из анализа зависимости кумулятивной вероятности резистивного переключения от напряжения (рис. $2, b)$. Следует отметить, что по сравнению с мемристорами на основе однородного РPX [14] мемристоры на основе PРX с НЧ серебра демонстрируют меньшие значения $U_{\text {set }}, U_{\text {reset }}$ и меньший разброс значений $U_{\text {set }}$ (коэффициент вариации 25\%).

Наблюдаемые эффекты РП (рис. 2,a) следует объяснять с учетом перколяционного характера проводимости 

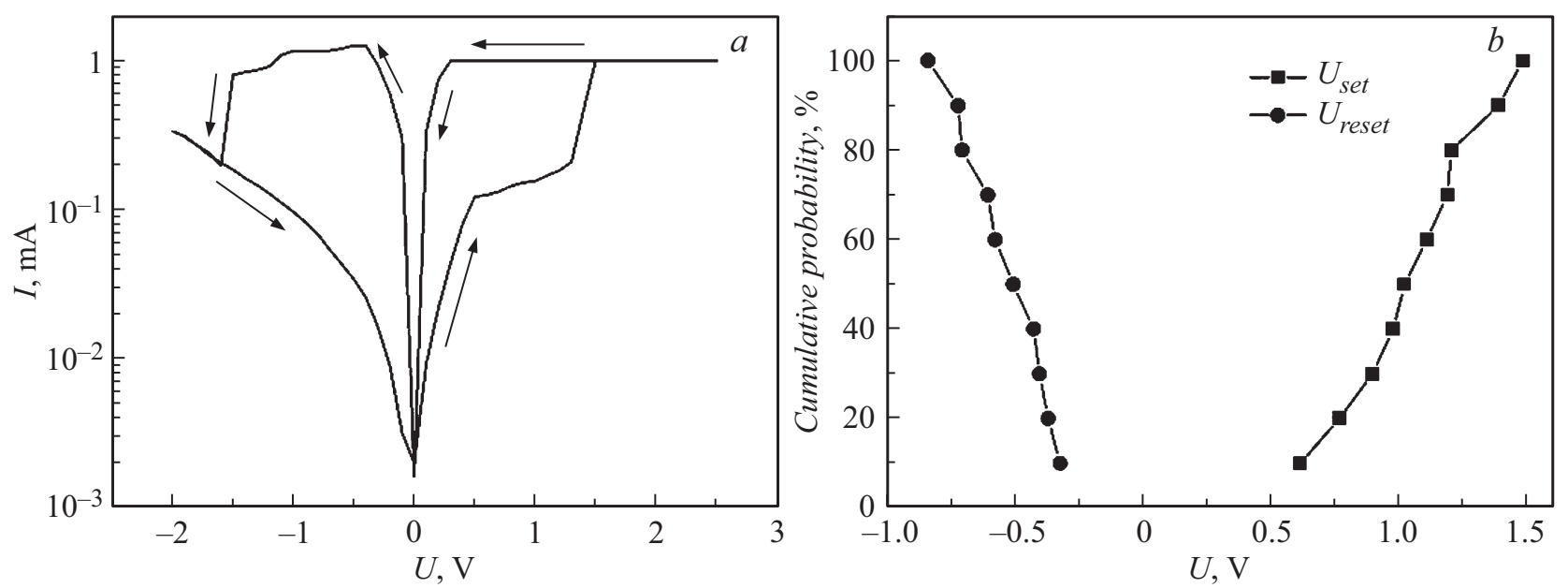

Рис. 2. $a$ - типичная вольт-амперная характеристика мемристивной структуры $\mathrm{Ag} / \mathrm{PPX}-\mathrm{Ag} / \mathrm{ITO} ; b-$ кумулятивная вероятность переключения исследованных мемристоров в состояние $R_{\text {on }}$ при напряжении $U_{\text {set }}$ и в состояние $R_{\text {off } f}$ при напряжении $U_{\text {reset }}$.
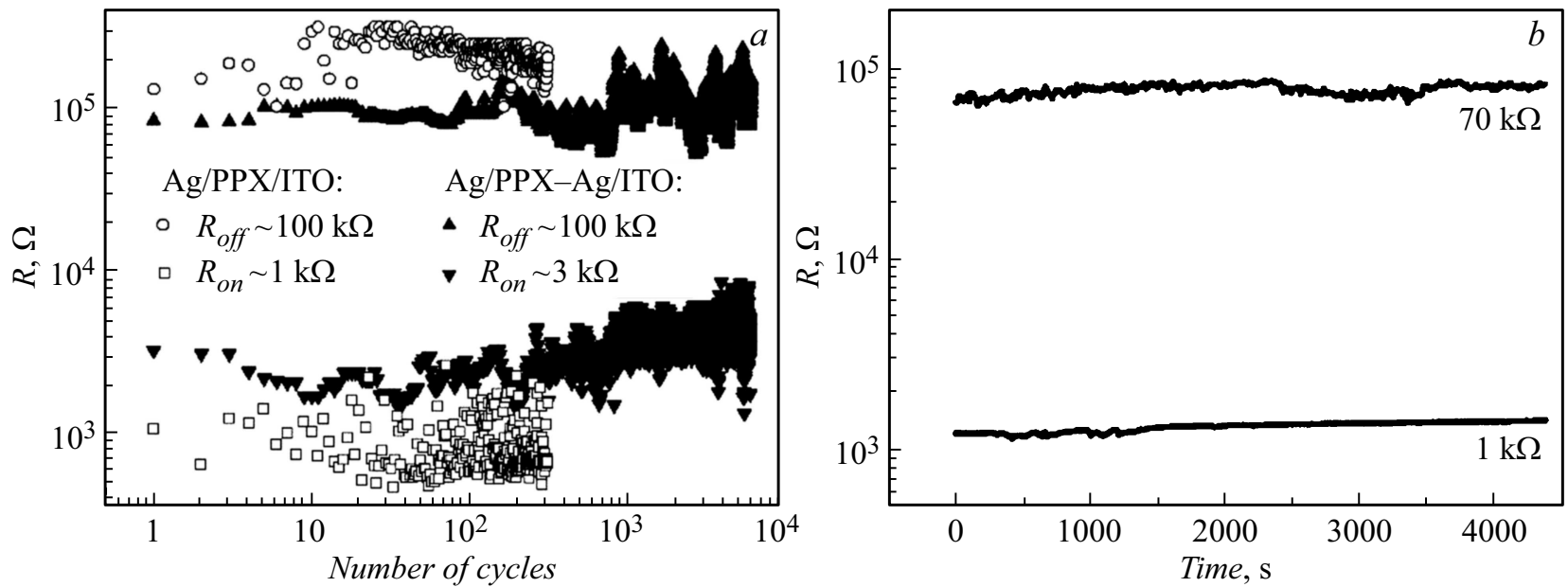

Рис. 3. $a$ - зависимость сопротивления от числа циклов переключения для мемристивной структуры Ag/PPX/ITO (кружки и квадраты) и $\mathrm{Ag} / \mathrm{PPX}-\mathrm{Ag} / \mathrm{ITO}$ (треугольники); $b$ - временнб́е зависимости сопротивления мемристивной структуры $\mathrm{Ag} / \mathrm{PPX}-\mathrm{Ag} / \mathrm{ITO}$ в высокоомном и низкоомном состояниях.

нанокомпозитной пленки, рассмотренного в [16], т.е. в рамках модели, отличной от предложенной в [19] для описания РП в мемристорах на основе однородного PРX. В структуре Ag/PPX/ITO переключение происходит по механизму электрохимической металлизации. При приложении положительного напряжения к верхнему электроду металлические ионы из него мигрируют через слой РРХ к нижнему электроду и восстанавливаются на нем. Таким образом, между верхним и нижним электродами образуется проводящий мостик, и мемристор переключается в состояние $R_{o n}$. Когда к верхнему электроду прикладывается отрицательное напряжение, самая тонкая часть проводящего мостика разрушается из-за джоулева нагрева и/или эффекта электронного ветра [20]. При этом часть катионов возвращается на верхний электрод, и мемристор переключается в состояние $R_{\text {off }}$. Такая модель объясняет и несимметричность $\mathrm{BAX}$ (рис. 2,a): для разрушения проводящего мостика требуются относительно большие отрицательные токи. Отличительная особенность нашего случая заключается в том, что перколяционные цепочки, формируемые металлическими $\mathrm{HЧ} \mathrm{Ag}$ в слое PРX, концентрируют поле и задают направление образования проводящего мостика аналогично случаю, рассмотренному в [16] при описании РП в конденсаторной структуре на базе неорганического нанокомпозита $\mathrm{CoFeB}-\mathrm{LiNbO}_{3}$. При этом подавляется стохастический характер РП, повышается их стабильность и уменьшается напряжение, необходимое для переключений.

Для использования исследованных мемристоров в НВС необходимо, чтобы они демонстрировали стабильные РП, а также могли сохранять состояния с различными сопротивлениями в течение длительного времени. На рис. $3, a$ представлена зависимость сопротивления от количества циклов переключения мемристивной струк- 
туры $\mathrm{Ag} / \mathrm{PPX} / \mathrm{ITO}$ и $\mathrm{Ag} / \mathrm{PPX}-\mathrm{Ag} / \mathrm{ITO}$. Структуры с $\mathrm{HЧ}$ серебра демонстрируют не менее 6000 стабильных циклов РП из состояния $R_{\text {off }}$ в $R_{\text {on }}$ и обратно, что более чем на порядок превосходит значение, достигнутое для структур на основе однородного РРХ $(\sim 300)$. Время сохранения двух различных резистивных состояний превышало час (рис. $3, b$ ), что сравнимо с результатами, полученными на структурах Ag/PPX/ITO [11].

Таким образом, исследованы мемристивные характеристики структур $\mathrm{Ag} / \mathrm{PPX}-\mathrm{Ag} / \mathrm{ITO}$. Показано, что введение НЧ серебра в матрицу РPХ приводит к улучшению большинства ключевых мемристивных характеристик: РП происходит при меньших значениях приложенного напряжения, увеличивается количество циклов переключения при сопоставимом времени сохранения высокои низкоомного состояний. Улучшение характеристик мемристоров может быть связано с наличием металлических НЧ в слое PРX, формирующих перколяционные цепочки, которые облегчают образование проводящих мостиков.

\section{Благодарности}

Измерения проведены с использованием оборудования ресурсных центров НИЦ „Курчатовский институт“.

\section{Финансирование работы}

Работа выполнена при финансовой поддержке Российского научного фонда (грант № 18-79-10253).

\section{Конфликт интересов}

Авторы заявляют, что у них нет конфликта интересов.

\section{Список литературы}

[1] Merrikh Bayat F., Prezioso M., Chakrabarti B., Nili H., Kataeva I., Strukov D. // Nature Commun. 2018. V. 9. P. 2331.

[2] Wang Z., Rao M., Han J.-W., Zhang J., Lin P., Li Y., Li C., Song W., Asapu S., Midya R., Zhuo Y., Jiang H., Yoon J.H., Upadhyay N.K., Joshi S., Hu M., Strachan J.P., Barnell M., Wu Q., Wu H., Qiu Q., Williams R.S., Xia Q., Yang J.J. // Nature Commun. 2018. V. 9. P. 3208.

[3] Cai F., Correll J.M., Lee S.H., Lim Y., Bothra V., Zhang Z., Flynn M.P., Lu W.D. // Nature Electron. 2019. V. 2. N 7. P. 290-299.

[4] Xia Q., Yang J.J. // Nature Mater. 2019. V. 18. N 4. P. 309 323.

[5] del Valle J., Ramírez J.G., Rozenberg M.J., Schuller I.K. // J. Appl. Phys. 2018. V. 124. N 21. P. 211101.

[6] Spiga S., Driussi F., Congedo G., Wiemer C., Lamperti A., Cianci E. // ACS Appl. Nano Mater. 2018. V. 1. N 9. P. 4633 4641.

[7] Mehonic A., Shluger A.L., Gao D., Valov I., Miranda E., Ielmini D., Bricalli A., Ambrosi E., Li C., Yang J.J., Xia Q., Kenyon A.J. // Adv. Mater. 2018. V. 30. N 43. P. 1801187.

[8] Ismail M., Nisa S.U., Rana A.M., Akbar T., Lee J., Kim S. // Appl. Phys. Lett. 2019. V. 114. N 1. P. 012101.
[9] Окулич Е.В., Коряэккина М.Н., Королев Д.С., Белов А.И., Шенина М.Е., Михайлов А.Н., Тетельбаум Д.И., Антонов И.Н., Дудин Ю.А. // Письма в ЖТФ. 2019. Т. 45. В. 14. C. 3-6.

[10] van De Burgt Y., Melianas A., Keene S.T., Malliaras G., Salleo A. // Nature Electron. 2018. V. 1. N 7. P. 386-397.

[11] Cai Y., Tan J., YeFan L., Lin M., Huang R. // Nanotechnology. 2016. V. 27. N 27. P. 275206.

[12] Zhou L., Mao J., Ren Y., Han S.T., Roy V.A.L., Zhou Y. // Small. 2018. V. 14. N 10. P. 1703126.

[13] Chen Q., Lin M., Wang Z., Zhao X., Cai Y., Liu Q., Fang Y., Yang Y., He M., Huang R. // Adv. Electron. Mater. 2019. V. 5. N 9. P. 1800852.

[14] Minnekhanov A.A., Emelyanov A.V., Lapkin D.A., Nikiruy K.E., Shvetsov B.S., Nesmelov A.A., Rylkov V.V., Demin V.A., Erokhin V.V. // Sci. Rep. 2019. V. 9. P. 10800.

[15] Li W., Liu X., Wang Y., Dai Z., Wu W., Cheng L., Zhang Y., Liu Q., Xiao X., Jiang C. // Appl. Phys. Lett. 2016. V. 108. N 15. P. 153501.

[16] Рыльков В.В., Николаев С.Н., Демин В.А., Емельянов А.В., Ситников А.В., Никируй К.Э., Леванов В.А., Пресняков М.Ю., Талденков А.Н., Васильев А.Л., Черноглазов К.Ю., Веденеев А.С., Калинин Ю.Е., Грановский А.Б., Тугушев В.В., Бугаев А.С. // ЖЭТФ. 2018. Т. 153. В. 3. C. $424-441$.

[17] Nikiruy K.E., Emelyanov A.V., Demin V.A., Sitnikov A.V., Minnekhanov A.A., Rylkov V.V., Kashkarov P.K., Kovalchuk M.V. // AIP Adv. 2019. V. 9. N 6. P. 065116.

[18] Григорьев Е.И., Завьялов С.А., Чвалун С.Н. // Рос. нанотехнологии. 2006. Т. 1. № 1-2. С. 58-70.

[19] Minnekhanov A.A., Shvetsov B.S., Martyshov M.M., Nikiruy K.E., Kukueva E.V., Presnyakov M.Y., Forsh P.A., Rylkov V.V., Erokhin V.V., Demin V.A., Emelyanov A.V. // Organic Electron. 2019. V. 74. P. 89-95.

[20] Веденеев А.С., Рыльков В.В., Напольский К.С., Леонтьев А.П., Клименко А.А., Козлов А.М., Лузанов В.А., Николаев С.Н., Темирязева М.П., Бугаев А.С. // Письма в ЖЭТФ. 2017. Т. 106. В. 6. С. 387-391. 